\title{
One Year of COVID-19 in the East African Community: An Overview of Response Activities
}

\section{Sina Odunsi $\mathrm{AB}^{1,2,3 *}$, Kirumbuyo $\mathbf{M}^{4,5}$, Adebayo $\mathbf{Y A}^{6,7}$, Ilesanmi $\mathbf{E}^{8,9}$, Sina Odunsi $\mathrm{AJ}^{3,10}$ and Nuga $\mathrm{BB}^{3,11,12}$}

${ }^{1}$ International Organization for Migration, United Nations Migration Agency, Mozambique ${ }^{2}$ Institute of Applied Health Sciences, University of Aberdeen, United Kingdom

${ }^{3} \mathrm{AB}$ Global Health Initiative, Nigeria

${ }^{4}$ Regional Office for the East and Horn of Africa, International Organization for Migration, Kenya

${ }^{5}$ Institute for Global Health and Development, Queen Margaret University, United Kingdom

${ }^{6}$ Global Health Focus Inc, United Kingdom

${ }^{7}$ Faculty of Pharmacy, University of Ibadan, Nigeria

${ }^{8}$ Department of Nursing, University College Hospital, Nigeria

${ }^{9}$ Faculty of Nursing Science, Ladoke Akintola University of Technology, Nigeria

${ }^{10}$ All Saints University College of Medicine, Saint Vincent and the Grenadines

${ }^{11}$ International Organization for Migration, United Nations Migration Agency, Nigeria

${ }^{12}$ Faculty of Public Health and Policy, London School of Hygiene and Tropical Medicine, United Kingdom

*Corresponding author: Ayomide Busayo Sina-Odunsi, AB Global Health Initiative, Sagamu, Nigeria, Email: maidas09@gmail. com

\section{Abstract}

COVID-19 continues to stress and strain health systems in many countries around the world and the East African community (EAC) is not exempted. The EAC is a regional intergovernmental organization of six partner states: the Republics of Burundi, Rwanda, Uganda and South Sudan, the United Republic of Tanzania, and the Republic of Kenya where the first COVID-19 case in the EAC was announced on 12 March 2020. Prior the emergence of the global outbreak, COVID-19, many countries in the EAC are being faced with the burden of communicable and non-communicable diseases, and the chronic challenge of ineffective response to public health emergencies. In this article, the authors comment on the COVID-19 response in the first one year of the outbreak in EAC and the challenges that faced the response activities.

Keywords: Covid-19; Rcce; Surveillance; Response; Outbreak

Abbreviations: EAC: East African Community; RCCE: Risk Communication and Community Engagement; EU: European Union.

\section{Introduction}

The 2019 Novel Coronavirus (COVID-19) was declared a Public Health Emergency of International Concern on 30
January 2020, and on 11 March 2020 it was characterized as a pandemic [1]. As the pandemic began to spread across the globe, Africa was not spared from its impacts on health systems. As of 12 March 2021, 4,005,204 cumulative cases and 107,001 deaths have been reported in 54 African countries and the countries with the highest number of confirmed cases on the continent are South Africa $(1,525,648)$, Morocco $(487,750)$, Tunisia $(239,977)$, Egypt $(189,000)$ and Ethiopia 


\section{Epidemiology International Journal}

$(171,210)$ [2]. The East African Community (EAC) is a regional intergovernmental organization of 6 Partner States: the Republics of Burundi, Kenya, Rwanda and South Sudan, the United Republic of Tanzania, and the Republic of Uganda, with the headquarters in Arusha, Tanzania [3]. The first case of COVID-19 in the EAC was reported in Kenya on 12 March, 2020. This was a Kenyan citizen who returned to Nairobi from the United States of America via London on 5 March 2020. She was confirmed positive by the Kenyan Ministry of Health [4].

Subsequently, Rwanda became the second country in the region to report a COVID case [5]. As of Friday, 12 March 2021, exactly one year after the first case was reported in the region, the number of cumulative COVID cases in the EAC has risen to 184,823 with 2,638 reported deaths and 134,572 recoveries [2]. The impact of the COVID-19 pandemic on countries in the EAC was expected to be more devastating than in high income countries. This is due to the population size, health status of the general population, weaker health systems and overall governance. This article aims to provide a commentary on the COVID-19 emergency response efforts over the past one year and the challenges facing the responses in the East African Community.

\section{COVID-19 Cases and Deaths in the EAC}

\section{Burundi}

On 31 March 2020, Burundi's Health Minister confirmed the country's first two cases of COVID-19. They were Burundi nationals who travelled back from Rwanda and Dubai respectively [6]. Burundian authorities confirmed the country's first COVID-19 related death on 13 April 2020 [7]. Following the first cases of COVID-19 reported, the Government of Burundi put in place a series of preventive measures, including screening tests, quarantine sites and the closure of borders, in an effort to contain the spread of the disease. As of 12 March 2021, a cumulative of 2,420 cases, 3 COVID-19 related deaths and 773 recoveries have been reported [2].

\section{Kenya}

The first case of COVID-19 was confirmed in Kenya on 12 March, 2020 [4]. On 15 March, Mutahi Kagwa, the Cabinet Secretary for Health announced that two more cases had been detected. These two people sat with the index patient aboard the flight in transit from the United States [8]. On the same day, the Kenyan President Uhuru Kenyatta directed measures to curb COVID-19. The first COVID-19 related death of a Kenyan citizen was reported on 26 March 2020 [9]. As of 12 March 2021, a cumulative of 111,935 cases,
1,901 COVID-19 related deaths and 88,209 recoveries have been reported [2].

\section{Rwanda}

On 14 March, 2020, the first case of COVID-19 was confirmed in Rwanda [5]. On 15 March 2020, the Ministry of Health reported 4 more people who tested positive for COVID-19 [10]. To curb the spread of the coronavirus, the Government of Rwanda immediately suspended schools, universities, places of worship across the country for two weeks. The government also banned large gatherings. The first COVID-19 related death was announced on 31 May 2020 [11]. As of 12 March 2021, a cumulative of 20,057 cases, 275 COVID-19 related deaths and 18,361 recoveries have been reported [2].

\section{South Sudan}

The first case of COVID-19 was confirmed on 5 April 2020 [12]. The second case of COVID-19 was confirmed on 7 April and the third case on 9 April who had been in contact with the first patient [13]. The first COVID-19 related death was registered on 14 May 2020 [14]. As of 12 March 2021, a cumulative of 9,334 cases, 104 COVID-19 related deaths and 11,951 recoveries have been reported [2].

\section{The United Republic of Tanzania}

The index case of COVID-19 in the United Republic of Tanzania was confirmed in Arusha on 16 March 2020 [15]. Tanzania registered its first COVID-19-related death on 31 March 2020 [16]. In May 2020, Tanzanian authorities stopped reporting case numbers, as of 08 May 2020, when the official reporting stopped, a cumulative of 509 cases, 21 COVID-19 related deaths and 183 recoveries had been reported [2].

\section{Uganda}

On 21 March 2020, the Ministry of Health of Uganda confirmed the first case of COVID-19 in the country [17]. On 24 March 2020, eight more cases were confirmed by the ministry of health and all were cases that came into the country between 17 and 20 March aboard Ethiopian and Emirates flights with some on board the same flight as the index case [18]. On 23 July 2020, The Ministry of Health announced that Uganda has registered the first COVID-19 related death [19]. As at 12 March 2021, a cumulative of 40,568 cases, 334 COVID-19 related deaths and 15,095 recoveries have been reported [2]. Table 1 below shows the total cumulative COVID-19 cases, deaths and recoveries reported in the EAC as at 12 March 2021 (Table 1). 


\section{Epidemiology International Journal}

\begin{tabular}{|c|c|c|c|}
\hline Country & Total Cases & Total Deaths & Total Recovered \\
\hline Burundi & 2,420 & 3 & 773 \\
\hline Kenya & $1,11,935$ & 1,901 & 88,209 \\
\hline Rwanda & 20,057 & 275 & 18,361 \\
\hline South Sudan & 9,334 & 104 & 11,951 \\
\hline $\begin{array}{c}\text { The United Republic of } \\
\text { Tanzania* }\end{array}$ & $509^{*}$ & $21^{*}$ & $183^{*}$ \\
\hline Uganda & 40,568 & 334 & 15,095 \\
\hline
\end{tabular}

*The United Republic of Tanzania stopped reporting cases officially in May 2020

Table 1: COVID-19 data in the EAC as of 12 March 2021.

\section{Response Activities}

\section{Risk Communication and Community Engagement}

Many EAC countries have risk communication and community engagement (RCCE) strategies to curb the spread of COVID-19 [1]. The RCCE response activities are rendered ineffective due to various challenges, such as distrust in government, cultural, social and religious resistance and inertia, as well as widespread rumours, stigma and issues of weak health systems [1].

\section{Burundi}

The country had its presidential election on 20 May 2020, and this undermined the country's response to COVID-19 including RCCE [20]. It was reported that authorities in Burundi had underestimated the consequences of the pandemic in the early days and relied on divine protection, instead of adopting specific COVID-19 containment measures to curb the pandemic [21]. On 12 May 2020, the Foreign Ministry of Burundi sent a notice that four World Health Organization (WHO) representatives should leave the country because it was perceived that the representatives were interfering with the country's COVID-19 responses. [22] However, this was due to the fact that the representatives were enforcing the containment measures. The government denialism had a major untoward impact on COVID-19 RCCE in the country [20]. However, partner organizations and agencies like UNICEF and WHO continue to urge the government to implement effective RCCE plans in Burundi [20].

\section{Kenya}

In response to the COVID-19 pandemic, the Federal Ministry of Health in Kenya started various containment activities to effectively contain the pandemic [23]. The government supported health and hygiene promotion activities and engagement of community and religious leaders for coordination and dissemination of contextually and culturally suitable messages and materials, with attention to marginalized vulnerable groups such as refugees, migrants and the elderly, as well as people living with co-morbidities and chronic diseases [24]. Several communication channels such as mainstream media, social media, community dialogue, government website, toll-free line, and SMS among other have been leveraged for RCCE in Kenya [24].

\section{Rwanda}

National health authorities in Rwanda have responded to the pandemic with innovative interventions to prevent and curb the spread of the virus [25]. The RCCE plans in Rwanda can be said to be innovative and some of the strategies include use of toll-free hotlines, use of WhatsApp for two-way engagement, use of drones for information dissemination, use of mass media and social media platforms and engaging religious leaders among others [25]. With the need to maintain and earn public trust, a RCCE team was set up to ensure a unified source of COVID-19 related information through government websites and social media in order to combat misinformation in Rwanda [26].

\section{South Sudan}

The country's National Ministry of Health and its health partners continues to mount response activities to curb the pandemic in the country [27]. South Sudan's plan for RCCE aimed to increase COVID-19 risk perception communication activities, ensure self-health care practices, promote physical distancing and to ensure regular and proactive (two-way) communication with at-risk (and/or affected) communities through appropriate channels [28]. The country is leveraging different communication channels for RCCE, which include TV and radio programs, social media, and telecommunication broadcasting (SMS, ringtones) among others. Community mobilizers, religious leaders and community leaders were also mobilized for RCCE in South Sudan [28]. 


\section{Epidemiology International Journal}

\section{The United Republic of Tanzania}

COVID-19 denialism by stakeholders in Tanzania remains a major concern to COVID-19 responses, including RCCE, across Africa and globally [29]. Even though partner organizations, civil society organizations and agencies like UNICEF are making effort to implement and advance RCCE, the overall state of COVID-19 response in the country continues to undermine proper understanding of the size of the pandemic in the country [30]. WHO and other agencies continue to urge government to educate and actively communicate with the public about COVID-19 using multiple communications techniques ranging from media and social media communications to mass communications [30]. Global health authorities are still hoping for Tanzania to strengthen its COVID-19 response including RCCE [31].

\section{Uganda}

The country's national health authorities and government employed both traditional and modern media including government websites to engage, mobilize, and sensitize the population on COVID-19 precautionary measures through regular updates [32]. The country was also leveraging a toll-free call center for COVID-19 community engagement [33]. WHO and the district health authorities as well as community mobilizers and religious leaders were engaging community members and individuals in the hotspot villages and other vulnerable regions on COVID-19 emphasizing the consequences if they failed to obey preventive measures [34].

\section{Surveillance Systems and Laboratory Testing Capacities}

Surveillance and detection system are critical components in monitoring the trend of disease and in response to a pandemic. In limiting the transmission rate of COVID-19, public health measures such as hand washing; physical distancing and wearing of masks are key preventive measures which are effective even on the new SARS-CoV-2 variants [35]. The African health system was not prepared for the COVID-19 pandemic in terms of laboratory testing capacity, and this led to setbacks in case identification, quarantine, and contact tracing. Countries in the EAC made effort to increase laboratory testing and have over time built the diagnostic capacity necessary to decentralize testing.

\section{Burundi}

Since the detection of the first cases of COVID-19, the government recommended preventive measures including hand washing, quarantine of travellers and the suspension of international commercial flights. The government also adopted guidelines that supported daily test of 5000
Burundians for 3 months; and a toll-free number was made available for hospitals in Bujumbura to trace suspected cases [36]. Upon resumption of duty, the newly elected president of Burundi initiated a mass screening campaign for COVID-19 which was successful in detecting many cases [37].

\section{Kenya}

In response to the first confirmed case, the government of Kenya traced and isolated 27 people that has had contact with the first case. When two of the quarantined tested positive to the virus. This prompted the Kenyan government to implement a series of strict preventive measures. The positive cases of COVID-19 rose to 22 on 1 April 2020, after which the President announced movements cessation in and out of The Nairobi metropolitan Area for the period of 21 days, extended the period of quarantine beyond 14 days and also declared mass testing of health workers and medical staffs [38]. In the first wave of the pandemic, Kenya struggled with testing capacities. In April 2020, Kenya received medical equipment from China which enabled the country to conduct wider testing for the coronavirus and prioritized high-density areas such as slums and high-risk areas such as hospitals and quarantine facilities [39]. By October 2020, Kenya had scaled up laboratories supporting COVID-19 testing from 2 to 39. The country also hired and trained a new cohort of healthcare workers to complement the existing capacity [40].

\section{Rwanda}

After Rwanda announced the first positive case in the country, this was followed by systematic contact tracing. The country began using systems and equipment it already had in place to address HIV. The structures, infrastructure, laboratory diagnostics and workforce used for COVID testing were already in place and were applied it to COVID testing [41]. The country began maximizing the healthcare workforce at the local government level, and this had been one of the strategies used in contact tracing at the community level to identify and link cases to test and care [42]. To address the rise in cases in the country's capital, Rwanda began implementing a random testing scheme in Kigali. They also set up a drive through testing scheme at the national stadium where people were randomly selected and asked to consent to the testing with result issues timely [43].

\section{South Sudan}

The country's healthcare system which had been drained by years of violence political and economic instability was not prepared to prevent or respond to a health emergency like COVID-19. After the first few cases were announced, 14-day quarantine was ordered for persons returning from outside 


\section{Epidemiology International Journal}

South Sudan and contacts of infected persons, also, returnees from other countries must provide certificate with indication of being negative. In early 2020, the government of South Sudan started looking for specialists in biology, microbiology and pathology to increase the laboratory workforce capacity. In a response to the cluster case among cross border truck drivers, COVID-19 testing was incorporated into health screening for all cargo drivers and passengers. To increase diagnostic capacity in response to COVID-19 pandemic, South Sudan received support from the WHO, the European Union (EU), China, who donated supplies to South Sudan's National Public Health Laboratory [44].

\section{The United Republic of Tanzania}

Since the first recorded cases of coronavirus, Tanzania practiced different surveillance measures which included suspension of school activities, mandatory 14-day quarantine for newly arrived international travellers with submission of a well detailed surveillance form to the Port Health Authorities upon arrival [45]. In May 2020, Tanzania had a complete U-turn on COVID-19 preventive measures and testing after President Magufuli concluded that results of tests on samples reportedly taken from sheep and goats were incorrect. The samples were reported tested positive [46]. In June, he declared the country free of the virus [47]. The new president of Tanzania urged residents of the country to observe preventive measures against coronavirus. Thereafter, the ministry of health reinforced the need for hand washing, healthy lifestyles and the use of face masks [48].

\section{Uganda}

The Ugandan governments began tracking and tracing individuals suspected of having COVID-19 right from when the first case was announced in the country. The government began to offer free COVID-19 testing in health facilities for patients who showed symptoms of the virus, contacts of confirmed positive cases and frontline health workers. Due to the increase in numbers of imported cases in the first wave of the pandemic, Uganda has made a decision to decentralize COVID-19 testing to high-risk areas such as points of entry. The Ministry of Health has developed a decentralized testing plan to target mobile lab testing and molecular testing [49]. The Ministry also accredited laboratories in the private sectors to do COVID-19 testing.

\section{Challenges Facing COVID-19 Responses in EAC}

Mistrust in government: Chronic political corruption results into large-scale distrust in governments and this leads to limited public cooperation and compliance to response protocols. This limits the outcomes of government responses to COVID-19 and facilitates the spread of the virus [50]. The distrust in government has negative impact and this is not an uncommon challenge across EAC in terms of their public health responses to COVID-19 and other public health emergencies [51]. Feeble healthcare systems: Despite the existing limited resources and weak health systems in EAC, the COVID-19 pandemic presented the countries with new challenges: the rapid need for sound public health response strategies. Effective COVID-19 response in countries in the EAC is hampered by limited resources, staff, and weak coordination mechanisms as well as limited funding and lack of plans and guidelines [52]. Countries in EAC are also facing direct burden of infectious and non-infectious diseases and the need to ensure response for these diseases, amid COVID-19, further complicated overall response measures. Pervasive poverty levels, uneven access to healthcare services and lack of response infrastructure has also made containment efforts challenging [53].

\section{Costs Implication}

Despite the accuracy, COVID-19 tests are not costeffective test for the average man to afford. This discourages many people from going for confirmatory tests, hereby leading to an acute underestimation in the number of reported cases as a high number of cases remain undetected.

\section{Pervasive Infodemic of Misinformation}

Widespread of rumours and misinformation continue to negatively impact COVID-19 response efforts in EAC and this is worsened by the social media [54]. However, in Tanzania, it has been reported the government was the one promoting COVID-19 denialism and spreading unscientific claims about the pandemic which is hampering effective RCCE in the county [30]. It is important that national health authorities need to move towards two-way feedback strategy, invest in the social media surveillance to address infodemic and to leverage tailored strategies for community engagement practices by using relevant languages, formats and channels to effectively curb the widespread rumours and misinformation.

\section{Conclusions and Recommendations}

COVID-19 pandemic within the first year of the outbreak has revealed how weak EAC can respond to public health emergency on the scale of a pandemic. We recommend reinforcing strategic mapping of partners, investing in proper coordination strategies, strengthening capacity building of response team, addressing mistrust through good leaderships, ensuring effective planning, and strengthening documentation and reporting of activities and experiences for public health emergency response in EAC. It is also 


\section{Epidemiology International Journal}

pertinent to assess existing response structures and to ensure approaches to support contextually tailored, specific, acceptable and right structure for future public health threat. EAC also need to integrate data and models in their approach to response to health emergency in order to strengthen their response capacity for the present and future outbreaks.

\section{Conflicts of Interests}

The authors declare that they have no competing interests.

\section{References}

1. Adebisi YA, Rabe A, Lucero Prisno DE (2021) Risk communication and community engagement strategies for COVID-19 in 13 African countries. Health Promot Perspect 11(2): 137-147.

2. Coronavirus Disease 2019 (COVID-19). Africa CDC.

3. Overview of EAC. East African Community.

4. Kagwe M (2020) First case of coronavirus disease confirmed in Kenya. Ministry of Health, pp: 1-3.

5. (2020) First Case of COVID-19 confirmed in Rwanda. WHO.

6. (2020) Burundi confirms first 2 COVID-19 cases. Anadolu Agency.

7. (2020) Burundi records first coronavirus death. The East African.

8. Kenya coronavirus cases rise to 3. Capital News.

9. (2020) First Kenyan dies of Covid-19. The Star.

10. (2020) Rwandan with no travel history diagnosed with COVID-19. Anadolu Agency.

11. (2020) Rwanda reports its first death from the new coronavirus. Reuters.

12. (2020) South Sudan confirms first case of COVID-19. World Health Organization South Sudan.

13. (2020) South Sudan records third case of COVID-19. Radio Tamazuj.

14. (2020)First COVID-19 Death Reported in South Sudan. Voice of America.

15. (2020) Tanzania confirms first case of Coronavirus. Voice of America.

16. (2020) Tanzania registers first Coronavirus death. The
East African.

17. Coronavirus disease (COVID-19) case confirmed. Ministry of Health Uganda.

18. (2020) Update on the Outbreak of COVID-19 in Uganda. Ministry of Health Uganda, pp: 1-2.

19. (2020) Update on the Outbreak of COVID-19 in Uganda. Ministry of Health Uganda.

20. Bagcchi S (2020) COVID-19 and measles: double trouble for Burundi. Lancet Microbe 1(2): e65.

21. (2020) Burundi: Any COVID-19 Cover-Up Will Put Lives at Risk. Human Rights Watch.

22. Burundi expels WHO coronavirus team as election approaches. The Guardian.

23. Wangari EN, Gichuki P, Abuor AA, Wambui J, Okeyo SO, et al. (2021) Kenya's response to the COVID-19 pandemic: a balance between minimising morbidity and adverse economic impact. AAS Open Res 4: 3.

24. (2020) Kenya National Communication and Community Engagement Strategy for Coronavirus. Compass, pp: 1-45.

25. Coronavirus Disease 2019, National Preparedness and Response Plan. Republic of Rwanda, Ministry of Health.

26. Karim N, Jing L, Lee JA, Kharel R, Lubetkin D, et al. (2021) Lessons Learned from Rwanda: Innovative Strategies for Prevention and Containment of COVID-19. Ann Glob Health 87(1): 23.

27. (2020) Enhancing COVID-19 response in South Sudan. World Health Organization South Sudan.

28. COVID-19 National Emergency Response Risk Communication, Social Mobilization and Community Engagement Strategy April-September 2020, pp: 1-3.

29. (2021) Tanzania's COVID Denialism Harms its Economic Future. Council on Foreign Relations.

30. Makoni M (2021) Tanzania refuses COVID-19 vaccines. Lancet 397(10274): 566.

31. Edwards N (2020) Tanzania's mild response to COVID-19 and its implications for the 2020 elections. Atlantic Council.

32. Kitara DL, Ikoona EN (2020) COVID-19 pandemic, Uganda's Story. Pan Afr Med J 35(S2): 51.

33. Kadowa I (2020) Using evidence and analysis for an 


\section{Epidemiology International Journal}

adaptive health system response to COVID-19 in Uganda in 2020. Ministry of Health Uganda.

34. (2020) When Community Engagement Restored Trust and Raised Public Index of Suspicion for COVID-19. WHO Afro.

35. (2020) WHO urges greater surveillance as new COVID-19 variants emerge. World Health Organization Africa.

36. (2020) Burundi: Fear, Repression in Covid-19 Response. Human Rights Watch.

37. (2020) Burundi launches mass screening campaign for Covid-19. TRTWORLD.

38. (2020) Govt announces extra measures to prevent spread of coronavirus Nairobi. Kenyan Ministry of Health.

39. (2020) Kenya to Start Mass Testing for COVID-19 with New Equipment From China. Voice of America.

40. (2020) Kenya scales up COVID-19 diagnostic capacity. Anadolu Agency.

41. Beaubien J (2020) Why Rwanda Is Doing Better Than Ohio When It Comes To Controlling COVID-19. National Public Radio.

42. Nachega JB, Atteh R, Ihekweazu C, Sam Agudu NA, Adejumo P, et al. (2021) Contact Tracing and the COVID-19 Response in Africa: Best Practices, Key Challenges, and Lessons Learned from Nigeria, Rwanda, South Africa, and Uganda. Am J Trop Med Hyg 104(4): 1179-1187.

43. Alfa Shaban AR (2020) Rwanda COVID-19: Places of worship reopen amid targeted lockdowns. Africa News.

44. (2020) South Sudan: EU and WHO increase access to diagnostics to tackle COVID-19. World Health
Organization.

45. Coronavirus-Tanzania: Travel Advisory No.1 of 23.03.2020 - Update on COVID-19 in Tanzania. African News.

46. (2020) Tanzania president questions coronavirus kits after animal test. AlJazeera.

47. (2020) Coronavirus: John Magufuli declares Tanzania free of Covid-19. BBC.

48. Owere P (2021) Tanzania's Ministry of Health now urges precaution against Covid-19. The Citizen.

49. Kaleebu P (2020) Performance Evaluation for COVID-19 Diagnostic tests. Uganda Virus Research Institute, pp: 1-20.

50. Ezeibe CC, Ilo C, Ezeibe EN, Oguonu CN, Nwankwo NA, et al. (2020) Political distrust and the spread of COVID-19 in Nigeria. Glob Public Health 15(12): 1753-1766.

51. Blair RA, Morse BS, Tsai LL (2017) Public health and public trust: Survey evidence from the Ebola Virus Disease epidemic in Liberia. Soc Sci Med 172: 89-97.

52. Covid-19 in Africa: Response areas. World Health Organization.

53. Ogunkola IO, Adebisi YA, Imo UF, Odey GO, Esu E, et al. (2020) Rural communities in Africa should not be forgotten in responses to COVID-19. Int J Health Plann Management 35(6): 1302-1305.

54. Osuagwu UL, Miner CA, Bhattarai D, Mashige KP, Oloruntoba R, et al. (2021) Misinformation About COVID-19 in Sub-Saharan Africa: Evidence from a CrossSectional Survey. Health Secur 19(1): 44-56. 